\title{
Function of Centrobin: a Novel Daughter Centriole-Associated Protein
}

\author{
Chaozhong Zou*, Jun Li*, Yujie Bai***, William T. Gunning**, David E. Wazer***, Vimla Band*, \\ Qingshen Gao*
}

* Division of Cancer Biology, Evanston Northwestern Healthcare Research Institute, Department of Medicine, Northwestern University Feinberg School of Medicine, 1001 University Place, Evanston, IL 60201;

** Department of Pathology, Biochemistry and Cancer Biology, Medical University of Ohio, Toledo, $\mathrm{OH}$

*** Department of Radiation Oncology, New England Medical Center, Tufts University School of Medicine, 750 Washington Street, Boston, MA.

In mammalian cells, a pair of centrioles and amorphous pericentriolar material constitute the centrosome, which plays a pivotal role in orchestrating formation of the bipolar spindle during mitosis [1-3]. Recent studies have demonstrated that centrosome activity is linked to cytokinesis and the activation of DNA replication [4-6]. The latter activity, which is physically associated with core centrosomal structures such as the centrioles or centriole-associated structures [4], probably is distinct from the microtubule organizing activities of the centrosomes.

In mammalian cells, the centrioles consist of nine triplets of microtubules, arranged in a cylinder of $200 \mathrm{~nm}$ in diameter and about $500 \mathrm{~nm}$ in length with additional filaments, fibers, and dense material attached to or inside the microtubular cylinder $[3,7]$. In addition to the $\alpha / \beta$ tubulin, only a small number of proteins has been found to localize to or be closely attached to the centrioles in mammalian cells. The centrioles duplicate once per cell cycle in a manner similar to DNA replication. Centriole duplication starts at the onset of the $\mathrm{S}$ phase, the two centrioles first separate, then a new (daughter) centriole forms in association with the mother centriole [8,9]. However, how this protein-based structure duplicates accurately remains completely unknown.

Here, we have identified a novel centrosomal protein, centrobin. Centrobin is predicted to have a coiled-coil region in its middle and non-coiled regions at the $\mathrm{C}$ - and $\mathrm{N}$-termini, as do some known centrosomal proteins such as pericentrin and ninein. In order to examine the expression and function of centrobin, we generated an anti-centrobin antiserum that can detect endogenous centrobin. This antibody was used to examine the localization of endogenous centrobin in a normal human mammary epithelial cell line $(76 \mathrm{~N})$ and several cancer cell lines (T47D, MCF10A, HeLa, COS, 293T, MCF7 and Capan-1). A typical centrosomal staining pattern was observed in all the cell lines, with one or two perinuclear dots in the interphase cells and a single focus at the end of each mitotic spindle in mitotic cells. The centrosomal staining was observed under three different fixation conditions (3.7\% formaldehyde, $100 \%$ methanol, or $0.5 \%$ glutaraldehyde) and also when cells were extracted with $0.5 \%$ Triton X-100 in $80 \mathrm{mM}$ PIPES, $1 \mathrm{mM} \mathrm{MgCl} 2$, and $5 \mathrm{mM}$ EGTA, $\mathrm{pH} 6.8$ before fixation. Furthermore, the centrosomal localization of centrobin was not affected by treatment with Nocodazole. These findings strongly indicated that centrobin is likely to be a bona fide core component of the centrosomes [10]. Importantly, GFP-centrobin and Myc-centrobin also localized to the centrosomes in the transfected cells when they were expressed at a very low level. During our initial immunolocalization analyses, we noted that the staining pattern of centrobin differed in cells that appeared to be at different phases of the cell cycle, suggesting the possibility that centrobin may 
differentially localize in either the mother or daughter centrioles. Through detailed analysis of centrobin localization during different phases of the cell cycle in 76NTert cells, NIH3T3 cells with a primary cilium, U2OS cells treated with HU, immunogold Electron microscopy, we have established that centrobin asymmetrically localizes to the daughter centrioles. It is particularly worthy of note that depletion of centrobin in HeLa cells resulted in a high percentage of both interphase cells and mitotic cells having two, one, or no centrioles, even under the condition of S-phase arrest, indicating that centrobin depletion inhibits the duplication of centrioles. Further analysis in U2OS cells arrested by HU treatment confirmed that inhibition of centriole duplication induced by centrobin depletion was not a consequence of cell-cycle arrest. We also found that $\gamma$-tubulin localization to the centrosomes is not visibly affected in cells with undetectable level of centrobin. Furthermore, centrobin depletion does not appear to affect microtubule organization and nucleation visibly in interphase cells. We have also demonstrated that the inhibition of centriole duplication by centrobin depletion leads to lengthening of mitosis and failure of cytokinesis in a substantial population of cells. The phenotype of cytokinesis failure upon centrobin depletion is strongly reminiscent of a phenotype mediated by rendering cells acentrosomal by microsurgical removal or laser ablation of centrosomes $[4,6]$. Thus, centrobin has a particularly important function in orchestrating centriole duplication. Additional structural and functional analyses are therefore likely to elucidate the mechanistic basis of a fundamental aspect of cell biology, namely, centrosome duplication.

1. Kellogg, D.R., M. Moritz, and B.M. Alberts, The centrosome and cellular organization. Annu Rev Biochem, 1994. 63: p. 639-74.

2. Zimmerman, W., C.A. Sparks, and S.J. Doxsey, Amorphous no longer: the centrosome comes into focus. Curr Opin Cell Biol, 1999. 11(1): p. 122-8.

3. Doxsey, S., Re-evaluating centrosome function. Nat Rev Mol Cell Biol, 2001. 2(9): p. 68898.

4. Hinchcliffe, E.H., et al., Requirement of a centrosomal activity for cell cycle progression through G1 into S phase. Science, 2001. 291(5508): p. 1547-50.

5. Piel, M., et al., Centrosome-dependent exit of cytokinesis in animal cells. Science, 2001. 291(5508): p. 1550-3.

6. Khodjakov, A. and C.L. Rieder, Centrosomes enhance the fidelity of cytokinesis in vertebrates and are required for cell cycle progression. J Cell Biol, 2001. 153(1): p. 237-42.

7. Beisson, J. and M. Wright, Basal body/centriole assembly and continuity. Curr Opin Cell Biol, 2003. 15(1): p. 96-104.

8. Vorobjev, I.A. and S. Chentsov Yu, Centrioles in the cell cycle. I. Epithelial cells. J Cell Biol, 1982. 93(3): p. 938-49.

9. Rieder, C.L., G. G. Borisy., The centrosome cycle in PtK2 cells: asymmetric distribution and structural changes in the pericentriolar material. Biol. Cell., 1982. 44: p. 117-132.

10. Oegema, K., W.G. Whitfield, and B. Alberts, The cell cycle-dependent localization of the CP190 centrosomal protein is determined by the coordinate action of two separable domains. J Cell Biol, 1995. 131(5): p. 1261-73. 